\title{
Have we become tolerant to PDA? A retrospective descriptive study over 16 years
}

\author{
Sadaf Bhayat, Justin Richards, Anay Kulkarni \\ St Georges University Hospital, London
}

\section{Background}

- Clinical consequences of patient ductus arteriosus (PDA) are related to the degree of left to right shunting through the ductus, creating an alteration of blood flow to vital organs. There is an association with intraventricular haemorrhage (IVH), bronchopulmonary dysplasia (BPD) and necrotising enterocolitis (NEC) ${ }^{1}$, however overall management remains uncertain².

- More neonates are managed conservatively but the long-term outcomes on the cardiovascular, pulmonary and neurodevelopmental systems remains unknown ${ }^{3}$.

\section{Aims}

1. To evaluate change in practise for management of PDA in preterm babies over 16 years.

2. To evaluate acute neonatal outcomes over 16 years, including death, bronchopulmonary dysplasia, grade IV intraventricular haemorrhage, necrotising enterocolitis, and retinopathy of prematurity (ROP) requiring laser treatment.

\section{Method}

- Retrospective observational study of all infants $<28$ weeks gestation admitted to a tertiary neonatal unit over 16 years (total of 1061 infants from 2002 to 2017).

\section{Results}



Graph 1. Rates of PDA treatment, Mortality, and ROP in infants <28 weeks from 2002 to 2017
- 269 infants (24\% of all infants born <28w GA) received treatment for their PDA over the last 16 years.

- Results were analysed in two Epochs

$$
\begin{aligned}
& >\text { Epoch 1: } 2002-2009 \\
& >\text { Epoch 2: } 2010-2017
\end{aligned}
$$

- $33 \%$ of infants born <28 weeks were medically treated for PDA during Epoch 1 compared to only 17\% of babies during Epoch 2 ( $p<0.001,95 \% \mathrm{Cl}$ [10.8-21.2]). All-cause mortality during Epoch 1 in babies $<28$ weeks was $18 \%$ versus $16 \%$ in Epoch $2(p=0.38)$ and incidence of ROP needing laser intervention was 3.9\%; versus $5.4 \%$ respectively $(p=0.25)$ (Graph 1$)$.

- Response to PDA treatment was analysed over 7 years (2010-2016). 17\% of PDAs had complete closure after treatment, and $50 \%$ became restrictive. In our unit the median time of treatment of PDA has remained constant (median 14 days of life - range 12-19 days) (Table 1).

\begin{tabular}{|cccccc|}
\hline Year & Total & $\begin{array}{c}\text { Median day } \\
\text { of initiation } \\
\text { of treatinent }\end{array}$ & & $\begin{array}{c}\text { Duct became } \\
\text { restrictive/cl } \\
\text { osed }(\%)\end{array}$ & $\begin{array}{c}\text { Duct closed } \\
(\%)\end{array}$ \\
\hline 2010 & 13 & 12 & $(4-29)$ & 60 & 15 \\
2011 & 15 & 13 & $(8-29)$ & 46 & 20 \\
2012 & 9 & 12 & $(8-23)$ & 66 & 11 \\
2013 & 12 & 18 & $(5-32)$ & 33 & 16 \\
2014 & 8 & 16 & $(7-19)$ & 75 & 50 \\
2015 & 18 & 19 & $(9-30)$ & 33 & 5 \\
2016 & 16 & 14 & $(7-23)$ & 50 & 6 \\
\hline
\end{tabular}

Table 1. Response to PDA treatment over 6 years and median time of treatment

\section{Conclusion}

Our unit has always followed a symptomatic strategy for the management of PDA's.

Time of initiation of treatment of PDAs has not changed, BUT fewer babies $<28$ weeks are being treated.

We have noted an increasing trend in incidence of ROP over the last 16 years, however this has not been corrected for a possible increased complexity in case load. We observed improving trend in mortality.

References:

1. Hammerman C. Patent ductus arteriosus. Clinical relevance of prostaglandins and prostaglandin inhibitors in PDA pathophysiology and treatment. Clinics in Perinatology 1995;22(2):457-79.

2. Evans N, Preterm patent ductus arteriosus: A continuing conundrum for the neonatologist? Seminars in fetal \& neonatal medicine, ISSN: 1878-0946, Vol: 20, Issue: 4, Page: $272-7$

3. Jain A, Shah PS. Diagnosis, Evaluation, and Management of Patent Ductus Arteriosus in Preterm Neonates. JAMA Pediatr.2015:169(9):863-872. 